\title{
Phytochemical Screening and Insecticidal Activity of Three Extracts of Tapinanthus bangwensis (Engl. \& Krause) on Sitophilus zeamais (Maize Weevil)
}

\author{
El Hadji Gorgui Diouf ${ }^{1,2 *}$, Moussoukhoye Diop', Aboubacary Sène ${ }^{1}$, Abdoulaye Samb1 \\ ${ }^{1}$ Laboratory of Natural Products, Department of Chemistry, Faculty of Sciences and Technology, University \\ Cheikh Anta Diop, Dakar, Senegal \\ ${ }^{2}$ Regional Centre for Ecotoxicology Studies and Environment Security (CERES-Locustox), Dakar, Senegal \\ Email: "goorgui82@yahoo.fr
}

Received 8 August 2016; accepted 26 August 2016; published 29 August 2016

Copyright (C) 2016 by authors and OALib.

This work is licensed under the Creative Commons Attribution International License (CC BY).

http://creativecommons.org/licenses/by/4.0/

(c) (i) Open Access

\begin{abstract}
In order to find alternative to synthetic pesticides, plants are increasingly used by farmers to protect stocks against crop pests. Thus, phytochemical and biological tests are performed on three organic extracts (cyclohexan, chloroform and methanol) of Tapinanthus bangwensis. The data were analyzed by the General Linear Model procedure using the software Minitab 16. These results showed that the methanol extract gives a better insecticidal activity on Sitophilus zeamais. RIZA software was used to calculate the LC50 of each extract. The cyclohexane extract gives an LC50 of $2.66 \mathrm{mg} / \mathrm{ml}$ after 18 days of treatment, while the chloroform extract and methanol respectively give $L C 50$ of $4.49 \mathrm{mg} / \mathrm{ml}$ and $6.99 \mathrm{mg} / \mathrm{ml}$ after 19 and 20 days of treatment.
\end{abstract}

\section{Keywords}

Extracts, Tapinanthus bangwensis, Sitophilus zeamais, Stored Food, Maize

Subject Areas: Agricultural Science

\section{Introduction}

The post-harvest losses have been one of the most important challenges of the African food problem. Between harvest and consumption, over 30\% of production is lost; this proportion is higher in Sahel region due to the

"Corresponding author.

How to cite this paper: Diouf, El H.G., Diop, M., Sène, A. and Samb, A. (2016) Phytochemical Screening and Insecticidal Activity of Three Extracts of Tapinanthus bangwensis (Engl. \& Krause) on Sitophilus zeamais (Maize Weevil). Open Access Library Journal, 3: e2962. http://dx.doi.org/10.4236/oalib.1102962 
long period of storage [1]. This problem concerns all food grown in the Sahel including maize.

In Senegal, the revival of the maize sector was initiated in 2003 in a large government program whose purpose was to improve the production due to a slight decrease between 1991 and 2000 [2]. Thus the production reached a high level that is never obtained again, nearly 510,236 t, according to the Agricultural Services and Forecasting and Statistics Services [3].

Maize production, after a fall of $43 \%$ in 2010 , from $329,000 \mathrm{t}$ to $186,000 \mathrm{t}$, would again be down of $33 \%$ in 2011 with 124,000 t [4]. The maize sector, therefore, is facing not only production difficulties but also postharvest storage. In 2003 a budget of 60 billion FCFA was scheduled (at 45,000 FCFA per farm) to cover storage needs at the producer level to reduce post-harvest losses, not counting the additional investments that processors should commit to meet their needs for processing and storage [5]. These storage problems are related to several factors, among which may be mentioned the attack of insect pests of maize stock, especially Sitophilus zeamais. To fight against these maize weevils the most commonly method is the use of synthetic insecticides (organophosphates and organochlorines). However, the use of synthetic pesticides poses problems of environment contamination, resistance of pest populations, and harmful effects on non-target organisms [6]. For thirty years, chemists, physiologists, biochemists, toxicologists and specialists of Plant Protection unite their efforts in the search for new molecules from plants to fight effectively against predators, with a minimum of environmental damage [6].

The objective of this work was to identify the different chemical groups present and to evaluate the biological activity of three extracts (cyclohexan, chloroform and methanol) of Tapinanthus bangwensis (Engl. \& Krause) on Sitophilus zeamais, an insect pest of maize stock. This plant, met in the department of Mbour, is used by the populations to protect their harvests. It is a parasitic plant which attends indifferently all the species of trees, but seems to be fond of the trees of gardens.

\section{Material and Methods}

\subsection{Material}

\subsubsection{Technical Material}

For this study, classical material made it possible to have access to the plants and to et al. make samplings while referring of work of Nguessan [7]. Drying was made in the shade and safe from the light before using an electric crushing for pulverization. An electronic balance is used to carry out the various weighings. A rotary evaporator, regulated with less $50^{\circ} \mathrm{C}$ to avoid the artifacts, is used for evaporations. This equipment also comprised spatulas, for the taking away of the powders of drug, of the absorbent cotton used like filter, a hood of protection against the powders ejected during the pulverization of drugs, a rod of trituration and grips besides the glassmaking. For thin layer chromatography (CCM), of the plates out of Silica glass are used for support, of the tanks and the pipettes Pasteur, a lamp UV (ultraviolet) for the observation of the spots. For the biological tests, limp of Petri of diameter $90 \mathrm{~mm}$ and of the pipettes Pasteur of brand LABMATE Software were used.

\subsubsection{Plant Material}

Vegetable material consisted of sheets and barks of stem of Tapinanthus bangwensis.

\subsubsection{Solvents}

For extraction, the identification tests, laboratory tests and TLC, we used different types of solvents:

- Ethyl acetate PA-ACS-ISO; Mininum assay (G.C.): 99.5\%; Identity: IR p/t.; Density at 20/4: 0.9000 - 0.902;

- Acetic acid PA-ACS-ISO; Mininum assay (G.C.): 99.5\%; Identity: IR p/t.; Density at 20/4: 1, 05;

- Cyclohexane (Reag. USP, Ph.Eur.) PA-ACS; Mininum assay (G.C.): 99.0\%; Identity: IR p/t.; Density at 20/20: 0.659 - 0.663;

- Chloroform (Reag. USP, Ph. Eur.) PA-ACS-ISO; Mininum assay (G.C.): 99.5\%; Identity: IR p/t.; Density at 20/4:1, 48;

- Dichmoromethan stabilized with amylene PA-ACS-ISO; Mininum assay (G.C.): 99.5\%; Identity: IR pt.; Density at 20/4: 1.323 - 1.325;

- Methanol (Reag. USP, Ph. Eur.) PA-ACS-ISO; Mininum assay (G.C.): 99.5\%; Identity: IR p/t.; Density at 20/4: $0.791-0.792$. 


\subsubsection{Biological Material}

The biological material consisted of maize bought at a market and Sitophilus zeamais obtained by mass rearing.

\subsection{Methods}

\subsubsection{Harvesting, Drying, Extraction and Mass Rearing}

\section{- Harvesting, drying}

The specimens were collected in the rural community of Keur Balla, located in the department of Mbour in the region of Thiès between the latitudes $14^{\circ} 02^{\prime}$ and $15^{\circ} 27^{\prime}$ North and longitudes $16^{\circ} 09^{\prime}$ and $17^{\circ} 12^{\prime}$ West. Thus, with the help of an old traditional healer, we collected leaves of Tapinanthus bangwensis. The plant material was dried in the shade with light for two weeks.

\section{- Extraction}

Technique used for extractions is the maceration during 24 hours with solvents of gradient of increasing polarity (Cyclohexane, Administers chloroform to and Methanol). The extract obtained is concentrated with assistance of a rotary evaporator during 15 minutes before being dried with the room temperature $\left(25^{\circ} \mathrm{C}\right)$ and safe from sun during 24 to 48 hours

\section{- Rearing of Sitophilus zeamais}

We got infested maize in the laboratory with which we operated sorting, recovered insects and we launched rearing. The rearing was done in boxes about $500 \mathrm{ml}$ volume. Inside each box, from 20 to 25 insects were put and hydrophilic cotton impregnated with water to create the necessary conditions of humidity for a good reproduction of the insects. We operated in the shade at room temperature (about $25^{\circ} \mathrm{C}$ ).

After 28 days, we observed emergences. Insecticidal activity tests were performed on insects of first generation that is to say, which were aged between 0 and 24 hours.

\subsubsection{Reagents}

For the identification and the description of the various chemical groups present in each extract, several types of reagents and witnesses were used while taking as a starting point the work by Bekro et al. [8]. For the identification and testing of different present chemical groups in each sample, several types of reagents and controls were used. For tannins, we used as control tannic acid and ferric chloride at $20 \%$ as revelator. Flavonoids and polyphenols were determined using Vitexin as control and Aluminium Chloride as reagent. The alkaloids were revealed through the reagent of Draggendorf using Cinchonin as control.

The reagent of Draggendorf is prepared starting from a solution made up of $0.85 \mathrm{~g}$ of basic nitrate of bismuth and $10 \mathrm{~g}$ of tartaric acid in $40 \mathrm{ml}$ of water (solution A) and a solution containing $16 \mathrm{~g}$ of $\mathrm{KI}$ in $40 \mathrm{ml}$ of water (solution B). Extemporaneously to mix $5 \mathrm{ml}$ of A, $5 \mathrm{ml}$ of B, $100 \mathrm{ml}$ of water and $20 \mathrm{~g}$ of tartaric acid.

\subsubsection{Phytochemical Screening}

The highlighting of different families of chemical compounds in Tapinanthus bangwensis is made by Thin Layer Chromatography (TLC) and by staining tests and precipitation. For the identification of different chemical groups by thin layer chromatography (TLC), we relied on the course of Bassene [8] on lipid extraction. For the identification of tannins, we used as eluent a mixture of ethyl acetate, methanol and water in the proportions of $40 \mathrm{ml}, 5 \mathrm{ml}$ and $8 \mathrm{ml}$ respectively. For this purpose, we used as the stationary phase glass plates covered of silica gel. The brown color of spots indicates the presence of tannin in the extracts. For flavonoids, the eluent used was a mixture of ethyl acetate and water (15\%). The stationary phase was glass plates covered with cellulose. The revelation was made with Aluminum Chloride and observation under UV at $254 \mathrm{~nm}$. The yellow coloring indicates the presence of flavonoids. Alongside the identification of flavonoids, may be that of the polyphenols with a UV exposure without direct use of reagents. Thus, there may be several luminescences with various colorations. To find saponins, we paid in a test tube, $10 \mathrm{ml}$ of aqueous total extract. The tube was agitated for $15 \mathrm{~s}$ and allowed to stand for 15 minutes. Height persistent foam than $1 \mathrm{~cm}$ indicated the presence of saponins [9].

\subsubsection{Biological Tests}

The biological tests are carried out in Petri dishes of $90 \mathrm{~mm}$ diameter. In each box, it had $20 \mathrm{~g}$ of maize and 25 insects aged from 0 to 24 . From each dry extract, we prepared five solutions of different doses $(100 \mathrm{mg} / \mathrm{ml}, 50$ $\mathrm{mg} / \mathrm{ml}, 25 \mathrm{mg} / \mathrm{ml}, 12.5 \mathrm{mg} / \mathrm{ml}$ and $6.25 \mathrm{mg} / \mathrm{ml})$. The solution 5 was obtained by taking $1 \mathrm{~g}$ of dry extract dis- 
solved in $10 \mathrm{ml}$ of solvent. The solution 4 was obtained by pipetting $5 \mathrm{ml}$ of the solution 5 supplemented with 10 $\mathrm{ml}$ of solvent. With the same method, we got the solution 3 from the solution 4, 2 from 3 and 1 from 2 . The tests were performed by spraying $500 \mathrm{ml}$ of each solution in the petri dishes with a Pasteur pipette. The test was repeated five times. The whole was then exposed to air for 20 minutes to evaporate the solvent. Insects were then introduced into each box.

\subsubsection{Statistical Analysis}

The measured variables are the number of dead insects, the number of surviving insects and the number of emerged insects. The calculated mortality was obtained by applying the formula of Aboth (1925): Mc = (Mo$\mathrm{Mt}) /(100-\mathrm{Mt}) * 100$ (where Mo = mortality in the treated groups, Mt = mortality in the control and Mc = calculated mortality). The variable number of dead insects, number of surviving insects and the number of emerged insects are subjected to analysis of variance model with three fixed factors (extracts, doses and time). The variable mortality was transformed to $\arcsin (\mathrm{x}=$ mortality rate, $\mathrm{n}=$ population size, $\mathrm{n}=1999)$ to standardize and stabilize the population variance. The General Linear Model method in Minitab 16 was used for statistical analysis of the data. The variables number of surviving insects and number of emerged insects have been undergone square root transformation to normalize the population and stabilize the variance.

\section{Results}

\subsection{Extraction Results}

From $64.154 \mathrm{~g}$ of powder of the plant (Tapinanthus bangwensis), we completed three cyclohexane, chloroform and methanol extracts. The results of the extractions were confined in the following Table 1.

\subsection{Phytochemical Study}

The table of phytochemical tests showed the presence of alkaloids in cyclohexane and chloroform extracts of the plant. Flavonoids were present in the methanol extract. The three cyclohexane, methanol and chloroform extracts, containall polyphenols. As for tannins, they were identified only with chloroform and methanol extracts. The research of saponins is positive in the aqueous extract of Tapinanthus bangwensis (Table 2).

1: Cyclohexan extract; 2: Chloroform extract; 3: Methanolic extract.

\subsection{Biological Tests}

The analysis of variance relating to the insecticidal effect of extracts of Tapinanthus bangwensis on Sitophilus zeamais revealed that the effect on mortality of the extract and that of the time was very highly significant $(\mathrm{P}<$ 0.001). Moreover, the effect of dose and the interaction of dose*extract were not significant $(P>0.05)$, this implies that the insecticide effect observed depended on the nature of the extract on the one hand and time other.

Table 1. Results of extractions.

\begin{tabular}{ccccc}
\hline Extracts & Aspect & Mass (g) & Yield & $3.27 \%$ \\
Cyclohexane & Powder & 2.097 & $2.20 \%$ \\
Chloroform & Powder & 1.414 & $14 \%$ \\
Methanolic & Pasty & 6.742 & $10.51 \%$ \\
\hline
\end{tabular}

Table 2. Results of phytochemical tests.

\begin{tabular}{|c|c|c|c|c|c|}
\hline Extracts & Alkaloids & Flavonoids & Polyphenols & Tannins & Saponins \\
\hline Cyclohexane & + & - & + & - & - \\
\hline Chloroform & + & - & + & + & - \\
\hline Methanolic & - & + & + & + & - \\
\hline Aqueous & - & - & - & - & + \\
\hline
\end{tabular}

+: presence; -: absence. 
For the emergence, we noted that the factors extract, dose and time had a significant influence $(\mathrm{P}<0.001)$ (Table 3). The Figure 1 and Figure 2 showed the mortality curve as a function of the extracts, the dose and time. The methanol extract protected well the treated medium. The evolution curve of treatment versus time showed that mortality was higher on days 1, 5 and 9; this implied that extracts Tapinanthus bangwensis had a short-term effect (Figure 1).

The Figures 3-6 showed the evolution of the emergence curve in function of extracts, applied doses and time. The cyclohexan extract provided good protection of the treated medium at doses 1 and 5 as well as the methanol extract. The chloroform extract also had a protective effect of the medium treated at doses 1 and 4 (Figures 7-10).

Table 3. Result of variance analysis of observed parameters.

\begin{tabular}{ccccc}
\hline Source of variation & DF & \multicolumn{2}{c}{ Mortality } & Emergence \\
Extract & & F & P & F \\
Dose & 2 & 31.03 & 0.000 & 21.19 \\
Extract-dose & 4 & 0.16 & 0.961 & 0.000 \\
Time & 8 & 0.31 & 0.962 & 0.086 \\
Total & 17 & 126.67 & 0.000 & 0.000 \\
\hline
\end{tabular}

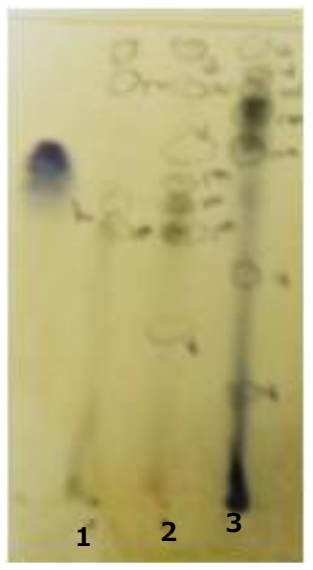

Figure 1. Plate revealing tannins.

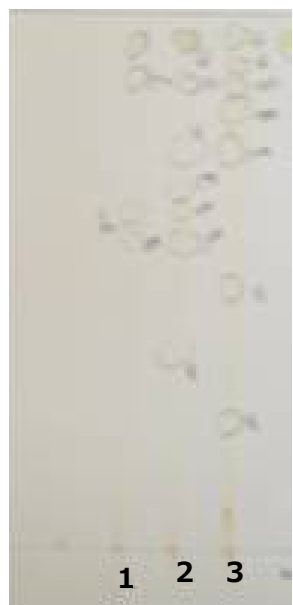

Figure 2. Plate revealing polyphenols. 


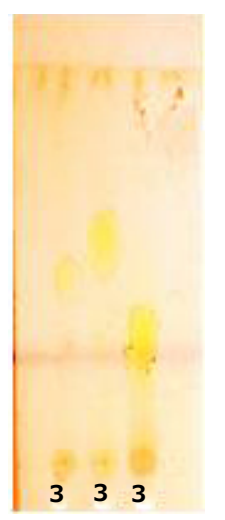

Figure 3. Plate revealing flavonoids.

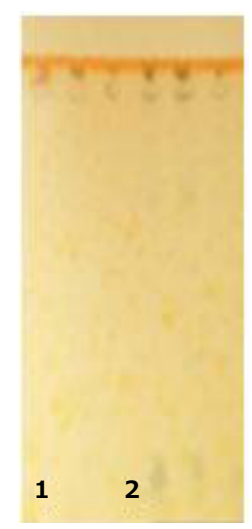

Figure 4. Plate revealing alkaloids.

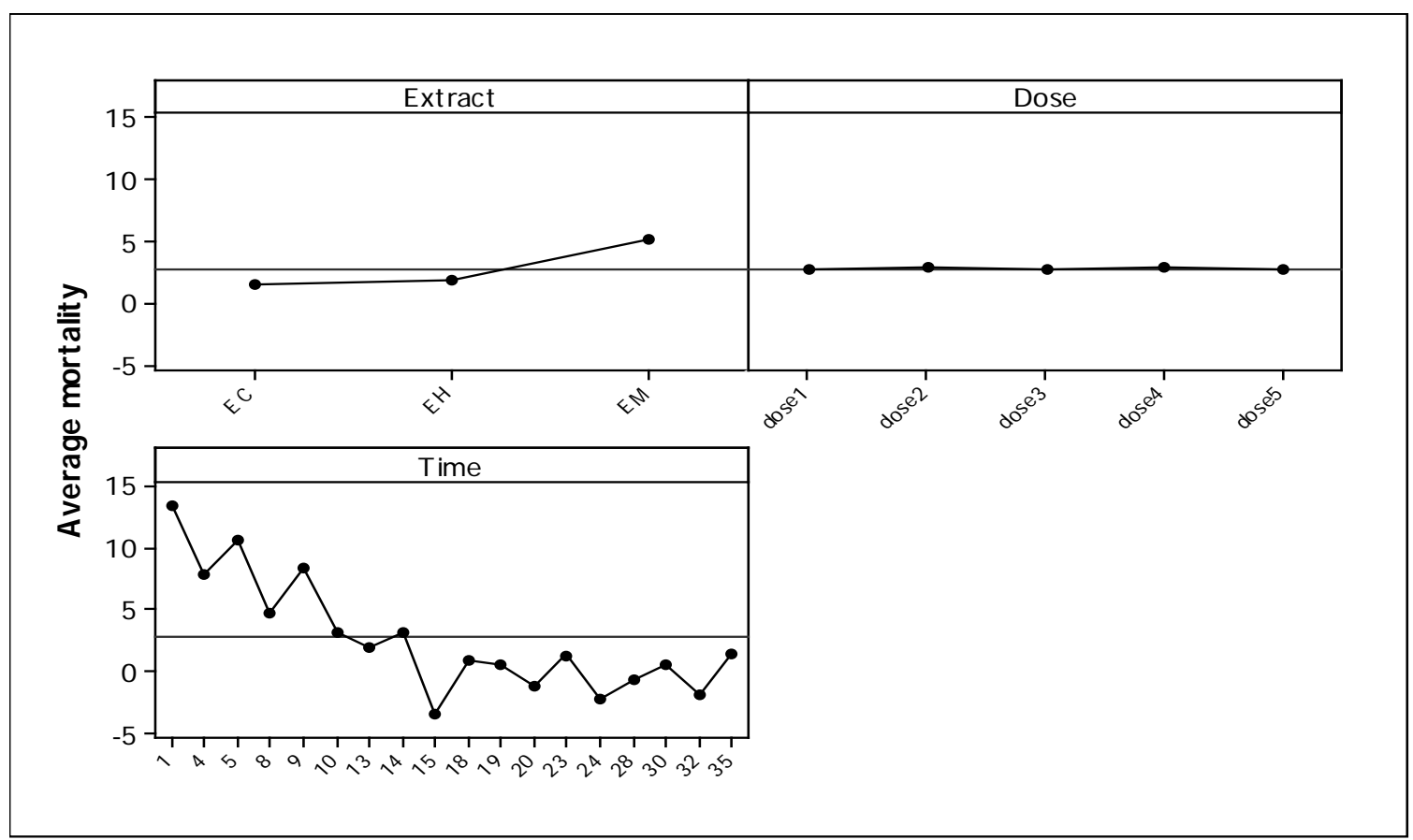

Figure 5. Curve of mortality in function of doses, extracts and time. EC: cyclohexane extract. EH: chloroform extract. EM: methanolic extract. dose 1: 6.25 g/l. dose 2: 12.5 g/l. dose 3: 25 g/l. dose 4: 50 g/l. dose 5: 100 g/l. 


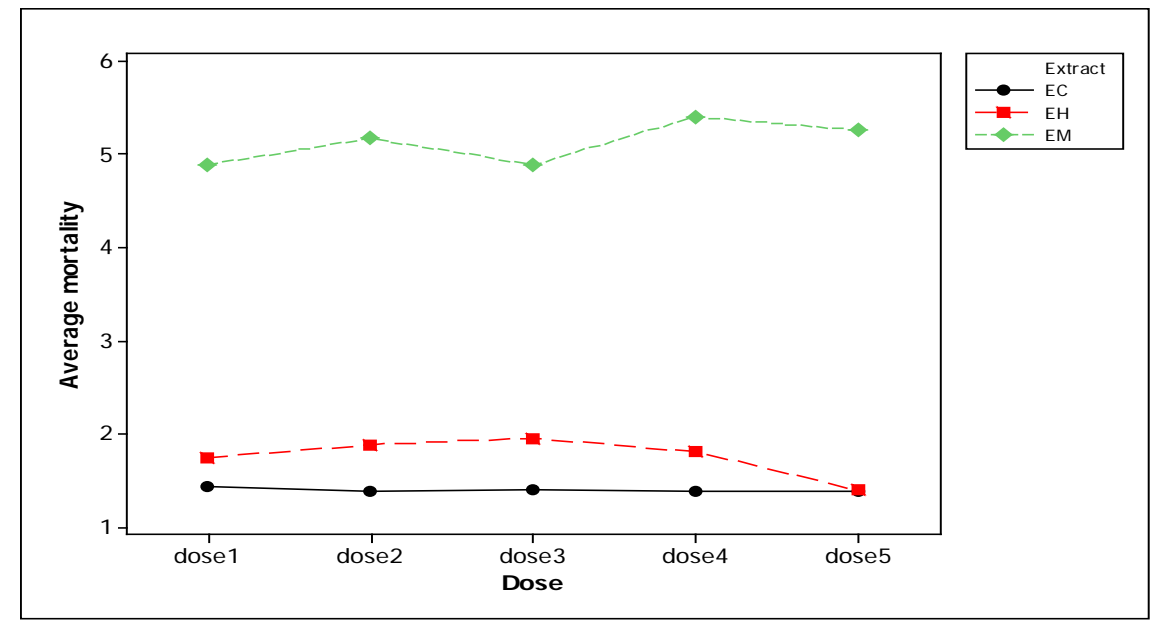

Figure 6. Interaction between extract, dose and time on mortality.

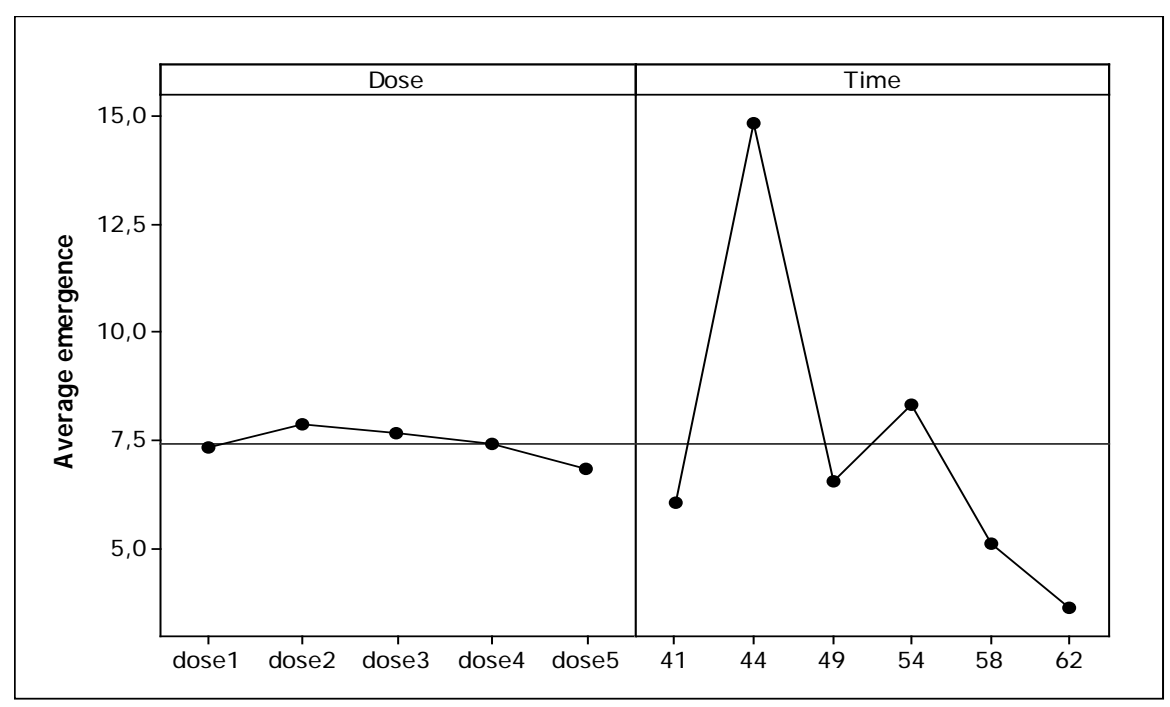

Figure 7. Curve of emergence with cyclohexan extract in function of dose and time.

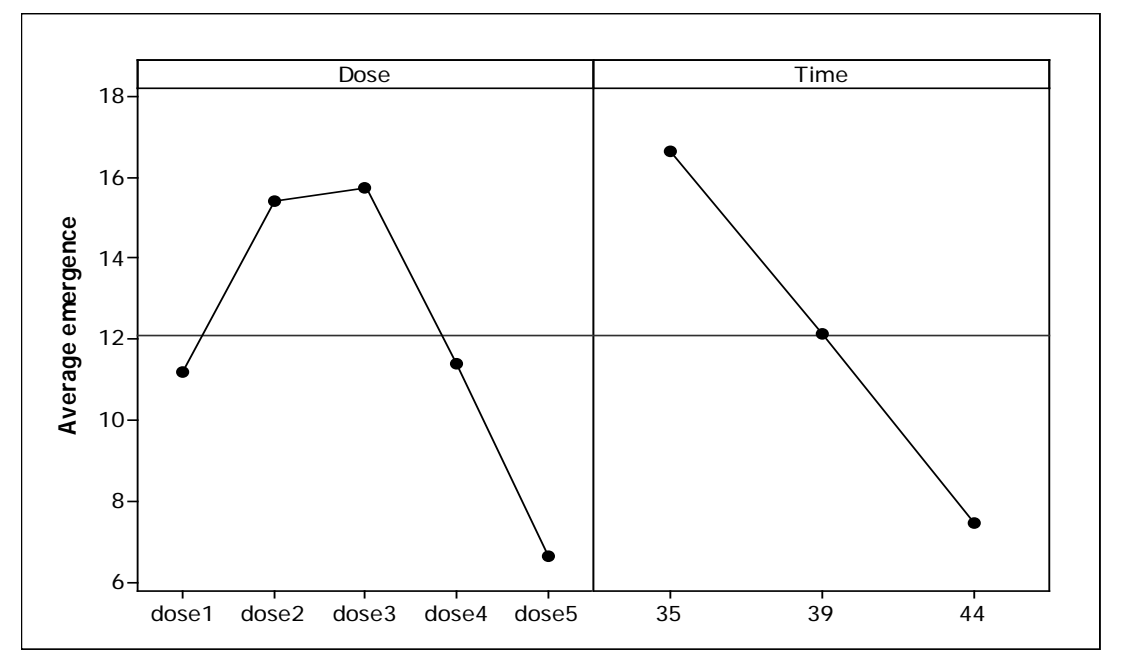

Figure 8. Curve of emergence with methanol extract in function of dose and time. 


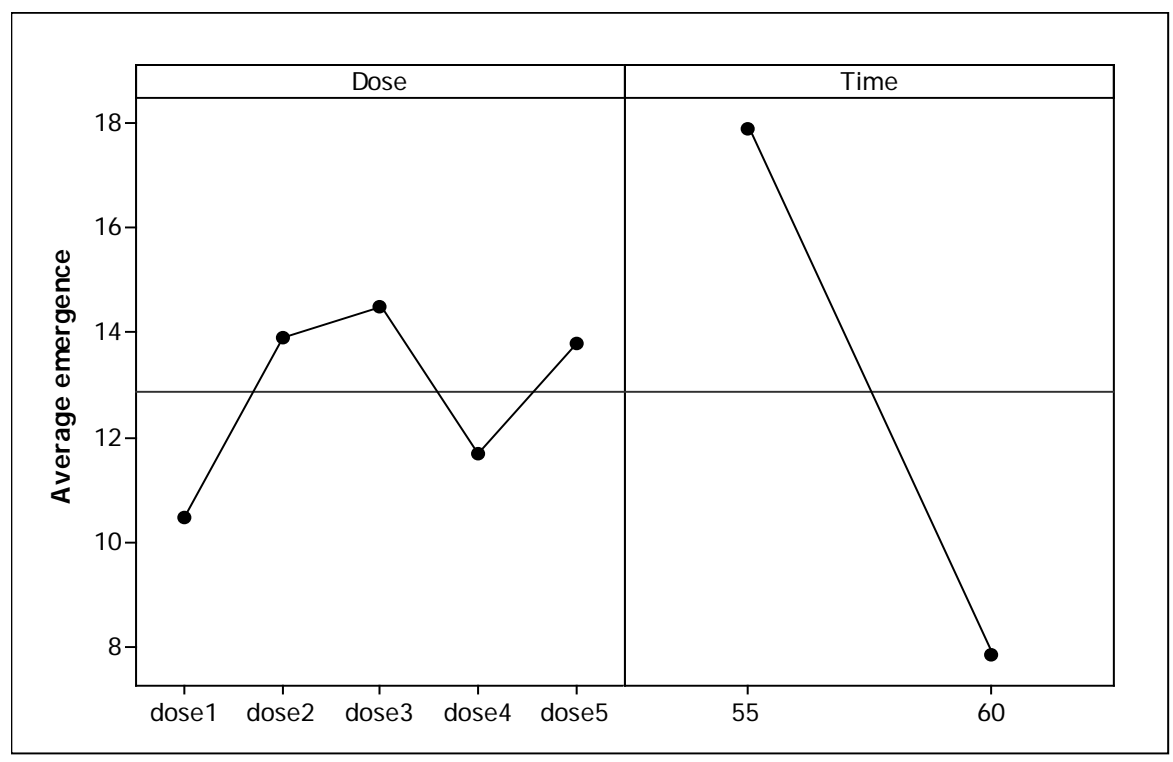

Figure 9. Curve of emergence with chloroform extract in function of dose and time.

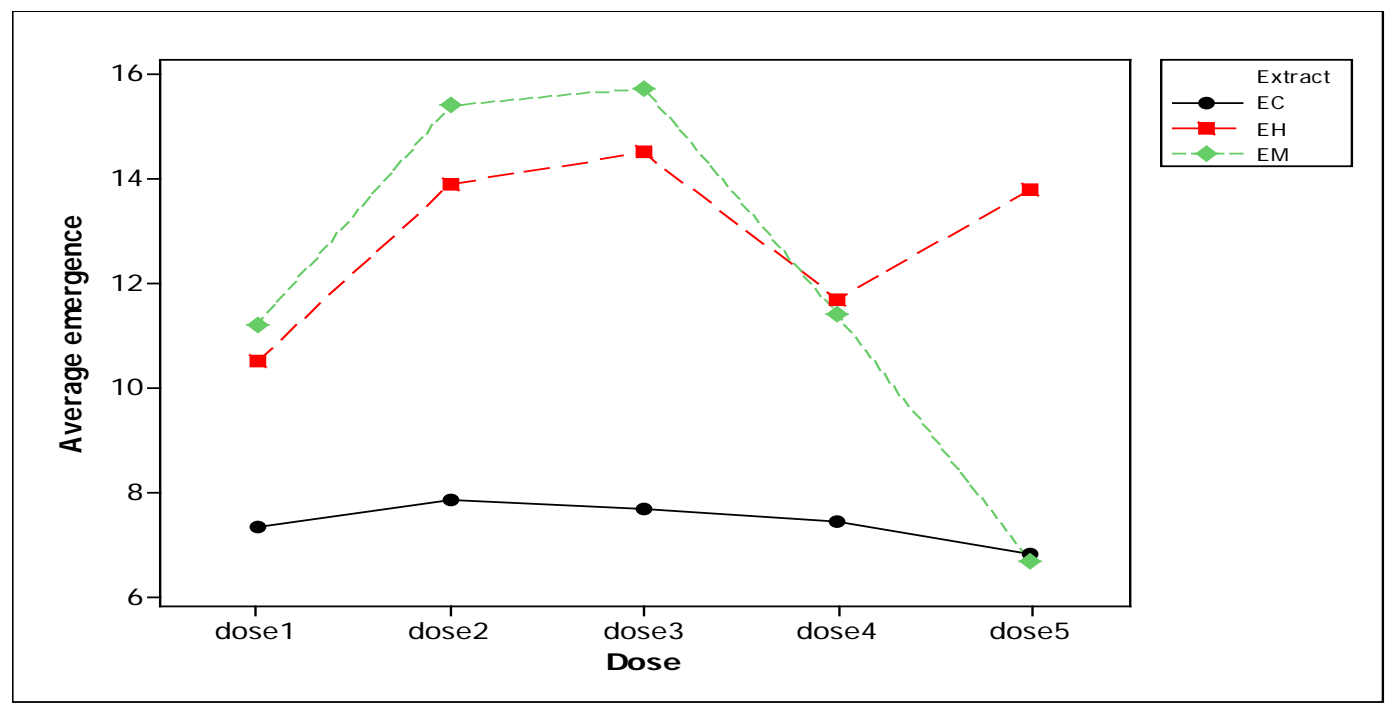

Figure 10. Interaction between extract and dose on insect's emergence.

\section{Discussion}

The effect of the methanol extract of Tapinanthus bangwensis is more significant on Sitophilus zeamais (maize weevil). Moreover, the results of phytochemical screening showed that the methanol extract contains tannin, polyphenols and flavonoids. The ubiquitous polyphenols in nature provocate a disturbance of the natural traction of insect. It can be fast the first day for quercetin or later on the fourth day for narangine, syringaldehyde or vanillic acid. It is accompanied in some cases (caffeic and ferulic acid, vanillin, luteolin 7-glucoside) a knock down effect. After eight days the insects are in a coma or dead state. The toxicity of polyphenolsis positively correlated with the attractive power of compound [10]. The tannins have a direct toxic effect on some insect species [11]. Tannins influence on growth, development and fecundity of several insect pests [12]. The reduction in growth caused by tannins has major disadvantages for the insect with a lower number of eggs and smaller eggs. This would affect the survival and health of individuals in the subsequent generation [13]. Thus, aromatic plants and their allelochemicals molecules exert a dual activity:

On adults by rapid toxic inhalation (monoterpenes) on the one hand and action which contributes to the insec- 
ticidal activity of the aromatic plant of a lower intensity but is exercised in the period (polyphenols);

On the different phases of the reproductive cycle: inhibition of fertility and larvicidal and ovocide activity at neonatal and later stages.

The insecticidal activity observed with the extracts with the Cyclohexan and the Chloroform of Tapinanthus bangwensis can be due to the presence of active ingredients similar to Viscotoxine. Kerharo and Adam [14] show that Tapinanthus bangwensis contains of Viscotoxin which is a toxic active ingredient.

The Angiosperms contain alkaloids which are secondary metabolites made up by the secondary nitrogen atoms, tertiary or quaternary in their structures [15]. They are active and play a significant role in the physiology of the plants or the organizations. The alkaloids have repulsive properties in the connection of the devastating insects [16].

Several studies showed that species of the family of Capparidaceae showed the insecticidal effect of the organic extracts on the devastating insects of stock of harvest. Among this work, it can quote those of Gueye et al. [17] which showed the insecticidal activity of Boscia senegalensis on Caryedon serratus (groundnut beetle). Many work also showed that the organic extracts of plant give insecticidal effects on the devastating in sects of stored food products. The toxicity of the extracts with organic solvents of Afrostyrax lepidophilus, Trichilia gilgiana, Drypetes gossweileri and Zanhagolungensis with regard to Sitophilus zeamaïs, Tribolium castaneum and Rhyzopertha dominica is shown by work of Aba Toumnou 22 [18].

\section{Conclusion}

The biological tests of the three extracts of Tapinanthus bangwensis on Sitophilus zeamais show that methanol offers better insecticidal activity extract. This result is also corroborated by the phytochemical study of the different extracts. Thus, this extract will be subject to bio-guided fractionation to isolate the active principle(s).

\section{References}

[1] Hance, N.Th. (2007) Diversity of the Ravageurs of the Food Products and Alternative Methods of Fight in Tropical Medium. Tropicultura, 25, 215-220.

[2] Ndiaye, A., et al. (2005) Cereals. In: Assessment of Agricultural and Agroalimentary Research in Senegal, Senegalese Institute of Agricultural Research (ISRA), Dakar, Food Institute of Technology (ITA), CIRAD, 241-256.

[3] Fall, A.A. and Dieye, P.N. (2008) Impact of World Rates of Rice on Food Safety in Senegal. Perspect Reflections. Senegalese Institute of Agricultural Research, 6-6.

[4] ANSD (2012) Economic Situation and Social of Senegal in 2012. Division of Documentation, the Diffusion and the Relations with the Users.

[5] FAO (1998) The Corn in the Human Nutrition. United Nations Organization for the Food and Agriculture (FAO) and the Information network on the Operations after Harvest (INPhO).

[6] Regnault-Roger, C., Philogene, B.J.R. and Vincent, C. (2008) Biopesticides of Vegetable Origin. 2nd Edition, Lavoisier, Paris, 550.

[7] N'Guessan, K., et al. (2009) Screening Phytochimic of Some Medicinal Herbs of the Ivory Coast Used in Country Krobou (Agboville, Coast-of Ivory). Sciences \& Nature, 4, 5.

[8] Bekro, Y.A., Bekro, J.A.M., Boua, B.B., Tra, B.F.H. and Ehile, E.E. (2007) Ethnobotanic Study and Screening Phytochimic of Caesalpinia benthamiana (Baill.) Herend. and Zarucchi (Caesalpiniaceae). Sciences and Nature, 4, 217-225.

[9] Bassène, E. (2012) Introduction to Research Natural Substances: Extraction-Analysis-Biological Test. University of Dakar Press, Dakar.

[10] Regnault-Roger, C., Ribodeau, M., Hamrauoui, A., Bareau, I., Blanchard, P., Gil, M.I. and Tomas Barberan, F. (2002) Disturbance of Acarthoscelides obtectus (Bruchidae. Cleoptera) Behavior by Polyphenolic Compounds Identified in Insecticidal Labiatae Botanicals. Journal of Stored Products Research (Review).

[11] Raymond, V., Barbehenn, C. and Constabel, P. (2011) Tannins in Plant-Herbivore Interactions. Phytochemistry, 72 , 1551-1565. http://dx.doi.org/10.1016/j.phytochem.2011.01.040

[12] Vandenborre, G., Smagghe, G. and Van Dammea, J.M. (2011) Plant Lectins as Defense Proteins against Phytophagous Insects. Phytochemistry, 72, 1538-1550. http://dx.doi.org/10.1016/j.phytochem.2011.02.024

[13] Meric, K. (2005) Studies on the Compounds Polyphenolic in Relation to the Food of the Tortrix of the Buds of the Virginal (Choristoneura fumiferana (Clem.)). Doctorate, Forest Sciences, Université Laval, Canada.

[14] Kerharo, J. and Adam, J.G. (1974) The Traditional Senegalese Pharmacopeia. Medicinal Herbs and Poisons, Vigot 
brothers, Paris, 1007 p.

[15] Bruneton, J. (2009) Pharmacognosy-Phytochemistry, Medicinal Herbs. 4th Edition, Re-Examined and Increased, TCE \& Doc., Paris, 1288 p.

[16] Pelletier, S.W. (2001) Alkaloids: Chemical and Biological Perspectives. University of Georgia, USA, 656 p.

[17] Gueye, M.T., Seck, D., Ba, S., Hell, K., Sembene, M., Wathelet, J.-P. and Lognay, G. (2011) Insecticidal Activity of Boscia senegalensis (Pers.) Lam ex Poir. on Caryedon serratus (Ol.) Pest of Stored Groundnuts. African Journal of Agricultural Research, 30, 6348-6353.

[18] Lucie, A.T. (2013) Integrated Management of the Principal Devastating Insects of Cereals by the Use of the Secondary Metabolites of the Indigenous Plants of Senegal and Central Africa. Doctorate Thesis, Production and Protection of the Plants, UCAD.

\section{Submit or recommend next manuscript to OALib Journal and we will provide best service for you:}

- Publication frequency: Monthly

- 9 subject areas of science, technology and medicine

- Fair and rigorous peer-review system

- Fast publication process

- Article promotion in various social networking sites (LinkedIn, Facebook, Twitter, etc.)

- Maximum dissemination of your research work

Submit Your Paper Online: Click Here to Submit

Contact Us: service@oalib.com 